\title{
Hypnotherapy in management of delivery pain: a review
}

\author{
Susan Azizmohammadi, Sima Azizmohammadi \\ Department of Gynecology, AJA University of Medical Sciences, Tehran, Iran \\ This article is distributed under the terms of the Creative Commons Attribution Noncommercial License (CC BY-NC 4.0) which permits \\ any noncommercial use, distribution, and reproduction in any medium, provided the original author(s) and source are credited.
}

\begin{abstract}
Hypnosis in obstetrics is available for more than one hundred years, but the development of inhalational anesthetic and chemotherapy agents and anesthesia drugs pending the 19th century induced the decrement of its application. However, experimental assessment of this type of intervention on labor and delivery in not high yet. For this reason, evaluation of hypnotic techniques in preparing childbirth should be carried out. One of the main unified mind-body healing practices, which has a great remedial potential in different applications of health care like labor and delivery. Assessment of effectiveness of this procedure in various administered trials is not easy, due to methodologic challenges, like normalizing trial conditions and picking up sufficient sizes of sample. Applying techniques of hypnosis for childbirth within hospital settings makes women to easily overcome barriers associated with institutional policies or caregiver resistance. Potential analgesic and anxiolytic clinical hypnosis effects for childbirth deserve more clinical trials. In this regard, nurses who manage women pending labor and delivery could easily enhance their skills and related understandings for contributing to techniques of hypnotherapy.
\end{abstract}

Key Words: Childbirth, hypnosis, hypnotherapy, hypnobirthing.

Eur J Transl Myol 29 (3): 210-217, 2019

Approximately one and half billion individuals would experience pain worldwide which could have inappropriate effects on their life. ${ }^{1}$ In spite medical intermediations could have a significant role in maintaining lives and maternal relief, they have become progressively usual in ordinary childbirth. This would rise the corresponding complications risk and also decrease experience of reasonable birth. Prenatal hypnotherapy could considerably reduce the pharmacological interventions requirements during childbirth. This study would assess the advantages of prenatal hypnotherapy for childbirth during pregnancy period. The application of hypnosis as a therapeutic technique could be impressive in reduction of pain and also decreasing the requirement of chemical anesthesia and also decreasing of fear, pain and anxiety associated with childbirth and delivery. ${ }^{2,3}$ Hypnosis is also an advantageous method for controlling different pregnancy complications and decreasing the probability of premature birth and labor in patients who are at higher risks. The hypnosis application in making the patients ready for delivery and birth is based on the assumption that such procedure could decrease anxiety, make tolerance of pain better, decrease the complications of birth and improve the process of recovery. ${ }^{4}$ The main perspective of this therapeutic procedure is collaboration of patient during the pregnancy and also before the start of delivery for assisting the patients to be included in their care and sense of control during delivery and labor process. The preparations of hypnosis make the women powerful to control their physical discomfort and anxiety. Additionally, successful hypnosis could be a simple, cheap method for amending the experience of childbirth, decrease complications correlated with pharmacological interventions, maternity care cost saving and also providing trustworthy documents for guiding clinical practice. ${ }^{5}$ One of the violent pain that could be experienced by women is labor, which illustrates both psychological and physiological challenge for women ${ }^{6}$ The most effective method of preparing pain relief during labor or/and delivery in comparison with no analgesia methods and regional analgesic techniques are mainly admitted to be the best usual pain relief methods in such situations. ${ }^{7}$ In spite the side effects of aforementioned techniques are generally known, they have internationally applied as they are considered to have an excellence profile of risk/benefit in the absence of alternatives. Anyway, the absolute elimination of labor pain via epidural analgesia does not certainly signify an experience of extra comfort birth for women and would 
Table 1. Hypnosis studies specifications for supervising management of delivery pain

\begin{tabular}{|c|c|c|c|c|c|}
\hline $\begin{array}{c}\text { Major } \\
\text { classification } \\
\text { of the study }\end{array}$ & $\begin{array}{l}\text { Related } \\
\text { studies }\end{array}$ & $\begin{array}{l}\text { Size of } \\
\text { sample }\end{array}$ & $\begin{array}{l}\text { Conditions of the } \\
\text { treatments }\end{array}$ & $\begin{array}{l}\text { Pain } \\
\text { extents }\end{array}$ & Main findings \\
\hline \multirow{4}{*}{$\begin{array}{l}\text { Comparison of } \\
\text { hypnosis and } \\
\text { standard medical } \\
\text { care }\end{array}$} & Cyna et al. ${ }^{12}$ & 3326 & $\begin{array}{c}\text { Hypnosis vs. } \\
\text { Standard med care }\end{array}$ & $\begin{array}{c}\text { Regional } \\
\text { epidural } \\
\text { analgesia }\end{array}$ & $\begin{array}{l}\text { Epidural analgesia is } \\
\text { more in standard } \\
\text { medical care }\end{array}$ \\
\hline & $\begin{array}{l}\text { VandeVusse } \\
\text { et al. }{ }^{13}\end{array}$ & 101 & $\begin{array}{c}\text { Auto hypnosis } \\
\text { Standard medical } \\
\text { care }\end{array}$ & $\begin{array}{l}\text { Regional } \\
\text { epidural } \\
\text { analgesia } \\
\text { Painkiller }\end{array}$ & $\begin{array}{l}\text { Analgesic medication } \\
\text { in auto hypnosis is less } \\
\text { The Apgar score of } \\
\text { auto hypnosis is higher }\end{array}$ \\
\hline & $\begin{array}{l}\text { Jenkins and } \\
\text { Pritchard, }{ }^{14}\end{array}$ & 862 & $\begin{array}{c}\text { Auto hypnosis vs. } \\
\text { Standard medical } \\
\text { care }\end{array}$ & Painkiller & $\begin{array}{l}\text { Analgesic medications } \\
\text { are less in auto- } \\
\text { hypnosis. } \\
\text { The stage one period } \\
\text { in auto hypnosis is } \\
\text { shorter than standard } \\
\text { medical care }\end{array}$ \\
\hline & $\begin{array}{l}\text { Martin et } \\
\text { al. }^{15}\end{array}$ & 60 & $\begin{array}{l}\text { Preparation of } \\
\text { hypnosis }\end{array}$ & Painkiller & $\begin{array}{c}\text { Preparation of } \\
\text { hypnosis had less } \\
\text { birth complications }\end{array}$ \\
\hline \multirow{2}{*}{$\begin{array}{l}\text { Comparison of } \\
\text { hypnosis with } \\
\text { supportive } \\
\text { psychotherapy } \\
\text { counseling }\end{array}$} & Letts et al. ${ }^{16}$ & 495 & $\begin{array}{l}\text { Auto hypnosis } \\
\text { Supportive } \\
\text { psychotherapic } \\
\text { counseling } \\
\text { Standard medical } \\
\text { care }\end{array}$ & Painkiller & $\begin{array}{l}\text { The application of } \\
\text { epidurals within auto } \\
\text { hypnosis is less than } \\
\text { supportive } \\
\text { psychotherapic } \\
\text { counseling and } \\
\text { standard med care }\end{array}$ \\
\hline & $\begin{array}{c}\text { Mehl- } \\
\text { Madrona }^{17}\end{array}$ & 520 & $\begin{array}{c}\text { Hypnosis vs } \\
\text { psychotherapy or } \\
\text { Standard medical } \\
\text { care } \\
\end{array}$ & $\begin{array}{l}\text { Epidural } \\
\text { drugs } \\
\text { Painkiller }\end{array}$ & $\begin{array}{l}\text { The application of } \\
\text { painkiller and epidural } \\
\text { drugs is less in } \\
\text { hypnosis }\end{array}$ \\
\hline $\begin{array}{c}\text { Comparison of } \\
\text { hypnosis with } \\
\text { psychoprophylactic } \\
\text { method }\end{array}$ & Venn $^{18}$ & 122 & $\begin{array}{c}\text { Psychoprophylactic } \\
\text { hypnosis vs } \\
\text { medical care }\end{array}$ & $\begin{array}{l}\text { Painkiller } \\
\text { Pain self- } \\
\text { ratings } \\
\text { and nurse }\end{array}$ & $\begin{array}{c}\text { There was no } \\
\text { difference between } \\
\text { psychoprophylaxis, } \\
\text { hypnosis and medical } \\
\text { care }\end{array}$ \\
\hline
\end{tabular}

be correlated with heavy complications. ${ }^{8}$ Effectiveness and invasiveness are two main factors in any applicable techniques, which have being used for obstetric population as analgesia adjunct. Hypnosis has been applied successfully where regional epidural analgesia is not advised as a course of treatment. ${ }^{9}$ On the other hand, hypnosis could block nearly all pain subjective perceptions throughout labor in about $30 \%$ of parturient women. The women reactivity to hypnosis seems to be rose in pregnancy period. In accordance with prevalent efficacy assertion, most researchers are aimed to investigate the hypnosis effects when applied for reduction of pain during childbirth and labor. ${ }^{10,11}$

\section{Materials and Methods}

A comprehensive search of the databases of PubMed and PsycINFO have done for satisfying the aimed criteria. Search phrases contained a mixture of pain, delivery, labor, hypnosis, interventions, treatment outcomes and analgesia. Table 1 sums up the main features of this comprehensive review such as every study sample size, conditions of the treatment experiment, pain extents and additionally the main findings. ${ }^{12-18}$ The major 
classification of related studies was including; comparison the performance of hypnosis with standard medical care, comparison the performance of hypnosis with psychoprophylactic method and comparison the performance of hypnosis with supportive psychotherapic counseling. However, for achieving the major aims of this review, studies were conducted in between subject's study design form in which an intervention of hypnosis was compared with a different intervention in diminishing labor or delivery pain.

\section{Discussion}

\section{Hypnosis experience}

The experiences of pregnant women about pain in labor are multiplex. Severity of pain worse by anxiety, tension and fear. Development of techniques like hypnosis could decrease childbirth anxieties and fears. Hypnosis is a modified condition of responsive awareness, which involves partly an attention focus to reduce external environment awareness. ${ }^{19}$ When individual's reactivity to communications rise in hypnosis, effective variations in behavior and perception are achieved. During the hypnosis the pregnant women could be guided by a professional person for the further use of self-hypnosis during labor. This prenatal training could be supplied by hypnotic audio recordings. Hypnosis during childbirth is mostly to focal attention on numbness of comfort feelings in addition to increment sense of safety and women's feelings of mental relax. ${ }^{20}$

\section{Antenatal trainings}

Tendency of women for pain relief anticipation with high level of satisfaction, pending delivery and labor, are not presently identified. ${ }^{21}$ Due to the increment of childbirth medicalization, many woman are looking for alternative relieving labor pain remedies. ${ }^{22}$ Losing the control of maternal feelings, anxiety and fear are the most frequent causes of the occurrence and severity of pain pending childbirth and also could enhance the risk of postnatal depression and post-traumatic stress disorder (PTSD). ${ }^{23}$ Since the mid-1980s it's proved that, the psychological intervention of hypnosis which could relieve pain and also anxiety. ${ }^{24}$ According to literature, hypnosis is a valuable and safe procedure which would be effectively applied during pregnancy and childbirth period of time. ${ }^{25}$ Nowadays, clinical hypnosis is a popular method whort to be studied by clinical trial research. In addition, brain imaging progression plays the main role in comprehension of neurophysiological variations happening during analgesia which achieved via hypnosis. ${ }^{26}$ The frontal part of the cingulate cortex has been frequently shown by application of positron emission tomography (PET) scan to be the main brain site which could be affected via pain hypnotic modulation. ${ }^{27}$ The neural activity suppression, amongst the primary structures within the limbic system and sensory cortex proves to prevent the emotional clarification of feeling being accomplished as pain.
During hypnosis procedure the focused attention would be limited, external stimuli awareness decrease and responses to action point will be increased. ${ }^{28}$ Action point are suggestions that would be appeared as verbal or nonverbal communications which could result in apparent spontaneous in behavioral or perceptional variations. These remedial communications would be conducted on the patient's unconscious and the responses are not dependent to any reasoning or conscious effort. Possibly medic hypnotic techniques can be applied only for decrement of pain during childbirth as a management method of woman's care. ${ }^{29}$ Anyway, in a practical manner hypnosis is known as an adventitious to enhance and simplify othr painkillers. About $30 \%$ of women could obtain perfect analgesia by application of hypnosis for reduction of pain during labor. ${ }^{30}$ The women reactivity to hypnosis during pregnancy would be increased. Practicing hypnosis techniques for applying during childbirth allows mothers to decrease their requirement for extra interventions and some medication that acts to relieve pain and increase successful natural vaginal births. ${ }^{31}$

\section{Explanation of the condition}

The pains which women will experience during labor are not such simple phenomena. In spite of that, nearly all women could experience various pain pending childbirth, their affective and sensational perceptions would be widely varying. ${ }^{32}$ As an instance, women explain labor sensations as to excessive muscular physical effort, some other define it as progressive pain, which indicates that the birth of their baby is close. In other cases pain appears as severe primary dysmenorrhea or/and describe it as torture. ${ }^{33}$ On the other hand, as reported by Grantly, ${ }^{34}$ sometimes women will experience nearly no labor pain and give birth accidentally. Additionally, Whitburn et al., ${ }^{32}$ mentioned psychosocial and physiological factors, which would clarify labor pain and its variation. Typically, labor pain has been described likewise acute pain which is a multiplex annoying sensory configuration, conceptual and experiences relating to a person's emotions and specified corresponding hysiologic, autonomic, behavioral and emotional responses. ${ }^{32}$ Anyway, dissimilar to other severe pains, which could often be assigned to pathologic procedures, labor pain would not be signaled as pathology or harm but could be considered as a normal part of birth. ${ }^{32}$ The physiological processes which could cause pain pending labor are including contractions of uterine which could be dilating the cervix during the labor first stage and the vagina stretching and also stretching of pelvic floor during the next labor stage when the baby descends. ${ }^{35}$ Physical elements like positions and posture women use in labor and pregnancy could affect pain. For instance, randomized controlled women to erect positions pending the firs labor stage less possibly to apply extradural analgesia than women randomized to horizontal positions. ${ }^{36}$ Psychosocial factors, such as self-efficacy 
feelings, fear, social support, coping strategies and anxiety have been demonstrated to be associated with women's historical experiences of labor pain. ${ }^{37}$ In contrast, as reported by Hodnett et al., ${ }^{37}$ application of pain relievers in women, who had a contiguous person supporting them during labor and also to increase women's confidence, could reduce the perception of pain. As mentioned by Chooi et al., ${ }^{38}$ within syndrome of fear-tension-pain, which is associated with women's feelings about anxiety and fear to muscular pain and tension during childbirth, numerous levels of maternal fear could induce the increment of muscular tension and consequently will cause extra pain and also enhancement of the woman's level of fear. ${ }^{38}$

\section{Explanation of the intervention}

A broad range of procedures for management of pain are applied at the present time by women pending childbirth and delivery. They include pharmacology procedures applied as physical or/and epidural analgesia procedures, like cold water therapy. The main hypnosis elements could be broadly characterized as involving diminished external motive awareness, the brain's ability to focus its consideration on a target and also reactivity to suggestions. ${ }^{39}$ These suggestions include application of words and sounds to express yourself and nonlinguistic transmission of information to achieve special remedial goals. ${ }^{25}$ In the context of delivery, suggestions would concentrate on rising safety senses, comfort and relaxation, in addition to analgesia sensations like numbing. There are two major procedures to supply interventions of hypnosis for delivery: auto hypnosis and/or hypnotherapy carried out by a practitioner. ${ }^{25}$ Auto hypnosis could be experienced by women, personally or within groups, and could be amplified with audio recordings to be applied at home. The main advantages of teaching women auto-hypnosis before delivery consist of enhanced sense of self control to manage discomfort and anxiety, and women's active participation approach. On the other hand, the delivering hypnotherapy was determined to be fewer time-consuming in comparison to antenatal training and also more powerful in predicting positive results. $^{40}$

\section{Comparing hypnosis with standard medical care}

Cyna et al. ${ }^{12}$ studied antenatal self-hypnosis for labor and childbirth. They investigated 77 of women who were pregnant for the first time and parous women who were self-selected for receiving hypnosis trainings. After 35 weeks of pregnancy the women were taught about hypnosis procedure and also were educated about the way of applying hypnosis as an alternative remedial method to other pain relief methods. Women who take part in Cyna et al. study experienced some special proposals for time dilation, satisfying relaxation and imagination, relief from pain, inability to feel pain, and the ability of tolerate contractions in a favorable way. The intervention of effective hypnosis was tagged as auto- hypnosis in spite of the fact that it is not clear that pregnant women were in a detailed manner demonstrated how to apply auto-hypnosis to experience the trained suggestions again. These results demonstrated that the women, who were pregnant for the first time and have experienced hypnosis, applied epidural painkiller less and also they have reduced requirement for the process of augmentation of labor with oxytocics in contrast with the control group. These outcomes demonstrated that, pending labor and delivery, hypnosis would have impressive reduction of epidural administration. Vandevusse et al., ${ }^{13}$ investigated hypnosis for childbirth within a retrospective comparative analysis of outcomes in one obstetrician's practice. Nearly half of self-selected participants, received trainings of auto hypnosis. Additionally, the control group which went under standard medical care and included 51 women who were similar to the group of hypnosis. The study outcomes demonstrated that, women who were under auto hypnosis trainings were provided less doses of sedatives and painkillers in contrast with the control group women. Additionally, women who were in the condition of hypnosis received less epidurals in comparison with those within the control condition. Jenkins and Pritchard describe theoretical considerations and practical applications of hypnosis in normal labor and delivery. ${ }^{14}$ The women within self-selected condition of hypnosis received thirty-minute training sessions that were provided via a hypnotherapist. The results of the study showed that, the women who were pregnant for the first time within the condition of auto hypnosis experienced considerably shorter stage one and stage two delivery, in comparison to the control group. In spite of the fact that, the women who has given birth once before and have received auto hypnosis trainings, would experience considerably shorter stage one labor in comparison with control group. At the end they proposed that auto hypnosis method would reduce the application of painkiller and also could reduce the labor length especially in women who were pregnant for the first time. ${ }^{14}$ Martin et al. investigated the effects of hypnosis on the labor processes and birth outcomes of pregnant adolescents. ${ }^{15}$ During their study, the women in group of hypnosis experienced adequate four-session training which included posthypnotic proposal for an ordinary delivery and labor, confidence and comfort feelings, an enhanced control sense, the women capability for entering hypnosis condition again and also experiencing pleasurable imagination of hypnosis pending a grievous constriction. Anyway, the group of hypnosis did not experience auto hypnosis courses and also direct intervention was not made during delivery and labor. The intervention of hypnosis was presented via family and marriage therapist. The control group experienced supportive psychotherapic counseling that could provide the opportunity of discuss concern issues which are associated with childbirth for patients. The results demonstrated that, women who underwent preparation of 
Table 2. Principles of theoretical analysis

\begin{tabular}{|c|c|c|c|c|c|c|c|}
\hline Study & $\begin{array}{c}\text { Cyna et } \\
\text { al. }{ }^{12}\end{array}$ & $\begin{array}{c}\text { VandeVusse } \\
\text { et al. }^{13}\end{array}$ & $\begin{array}{c}\text { Jenkins, } \\
\text { Pritchard }^{14}\end{array}$ & $\begin{array}{c}\text { Martin et } \\
\text { al. }^{15}\end{array}$ & $\begin{array}{c}\text { Letts et } \\
\text { al. }^{16}\end{array}$ & $\begin{array}{c}\text { Mehl- } \\
\text { Madrona }^{17}\end{array}$ & Venn $^{18}$ \\
\hline $\begin{array}{c}\text { Assignment } \\
\text { accidentally }\end{array}$ & No & No & No & Yes & No & Yes & No \\
\hline Sample characteristics & No & Yes & No & No & No & No & Yes \\
\hline $\begin{array}{c}\text { Medical treatment } \\
\text { guidebook }\end{array}$ & No & No & No & No & No & No & No \\
\hline $\begin{array}{c}\text { Remedial approaches } \\
\text { based on hypnosis } \\
\text { factors }\end{array}$ & Yes & Yes & Yes & Yes & Yes & Yes & Yes \\
\hline $\begin{array}{c}\text { Hypnosis operational } \\
\text { usage }\end{array}$ & No & Not clear & Not clear & No & $\begin{array}{c}\text { Not } \\
\text { clear }\end{array}$ & No & No \\
\hline $\begin{array}{c}\text { Mediation } \\
\text { suggestibility of } \\
\text { hypnosis }\end{array}$ & No & No & No & No & No & No & Yes \\
\hline
\end{tabular}

hypnosis had considerably fewer complications of birth and shorter length of stay in hospital. ${ }^{15}$

\section{Comparing hypnosis with supportive psychotherapic counseling}

Letts et al. worked on the application of hypnosis in labor and delivery within a preliminary study and also investigated the application of auto hypnosis in reduction of obstetric interventions usage. ${ }^{16}$ The participants were taught, with the help of a hypnotist, on using auto hypnosis for taking calm themselves and also the way of transferring glove anesthesia to the abdomen. The group of hypnosis was compared with an extra control group of patients who were taught via the help of another physician at the hospital. However, this group received just standard medical care. In comparison with supportive psychotherapic counseling and group of standard medical care, the women participants of the group of auto hypnosis experienced considerably less rates of epidural block. ${ }^{16}$ Mehl-Madrona evaluated the facilitation of hypnosis in painless birth and also the effect of hypnosis in reduction of labor/delivery length and birth complications. The participants were randomly specified for preparing of hypnosis with the supportive psychotherapy or one of the paper author with a female intern. The intervention of hypnosis highlighted some suggestions for decreased fear and anxiety in addition with social support, relaxation feelings. ${ }^{17}$ Visualization technique was applied to guide women by means of giving birth imaginary experience. Anyway, it is not clear if participants of hypnosis have experienced proposals of formal post-hypnosis or auto hypnosis training. The control group of women who were not treated was equalized to women with supportive psychotherapic counseling group based on race, parity, age, and statuses of birth risk and social-economic factors. The results demonstrate that women in the group of hypnosis presented less complex caesarean sections than those of the other two groups. ${ }^{17}$

Comparing hypnosis with psychoprophylactic method

Psychoprophylactic method is the major particularised form of preparation which confirms various methods of natural childbirth as the main substitute to the application of medical intervention. It involves psychotherapeutic process of cognitive restructuring of the women understandings of childbirth by concentrating on ways to building confidence and educating mothers about the giving birth process and anatomy. ${ }^{41}$ In addition, psychoprophylactic method could involve the application of a coach and educating relaxation breathing exercises. Venn within an exploratory study have investigated the brief communication of hypnosis and psychoprophylactic method and also assessed whether their combination could reduce pain and increase satisfaction or not. ${ }^{18}$ Participants within hypnosis conditions experienced preparation of hypnosis for being prepared for beginning of childbirth. Additionally, they experienced development of age by means of the birth experience, suggestions of post hypnosis to enter hypnosis during delivery and labor again and also guided via their imagination for achieving analgesia through walking in a cold water pool. On the other hand, the women who were prepared via hypnosis did not received any remedial intervention and auto hypnosis trainings pending delivery or/and labor. The results do not demonstrate any differences amongst mentioned interventions on women classifications of satisfaction and pain with the nurse pain ratings, analgesic therapy application and delivery process. ${ }^{18}$

\section{Theoretical analysis of the procedure}

One of the main considerations about the hypnosis efficacy as an intermediary procedure for reduction of 
delivery and labor pain is to investigate the analytical limitations of this field research. The assessment of reviewed studies based on 6 main analytical specifications are mention in Table 2. As could be seen, studies which followed the principles are specified with "Yes", studies which do not followed the principles are characterized by "No" and eventually if principle status was not seif-evident they are marked as "Not clear".

\section{Spontaneous vaginal delivery (SVD)}

The group of simple births contains only vaginal deliveries that happened spontaneously, while the group of complex births contains both assisted surgical birth and spontaneous vaginal delivery (SVD). Identifying all spontaneous vaginal births as a group is not possible, because when a woman had haemorrhage after SVD she was included in the group of complicated birth. ${ }^{42-44}$ As reported by Madden et al. ${ }^{2}$ not obvious variation could be discovered amongst women who experienced spontaneous vaginal delivery and the group of women who underwent hypnosis. On the other hand, the possibility of spontaneous vaginal birth between women who underwent hypnosis in the middle three months of their pregnancy could be greater. ${ }^{2}$

\section{General comments of verified studies}

Our general revision of verified studies proposes that hypnosis could be applied effectively as a powerful intervention in management of delivery and childbirth pain. Additionally, based on the previous studies hypnosis proved to be more advantageous than other common remedial procedures, traditionally childbirth procedures and supportive psychotherapic counseling. ${ }^{13}$ In accordance with Stoelb et al., ${ }^{45}$ hypnosis is able to perform better than other common interventions and medical cares in relieving pain. On the other hand, autohypnosis could be systematically more impressive than other conditions in pain reduction. ${ }^{12}$ However, auto hypnosis would be more advantageous if being taught pending the real process of childbirth. ${ }^{13}$ In spite of the fact that, hypnosis would be promised as an intervention for delivery pain it is not possible to conclude that it is definitely productive. Reinhard et al., reported that auto hypnosis is a more affective in reduction of application of analgesic medication and more impressive than any other common medical cares. ${ }^{46}$ Additionally, the effect of auto hypnosis is more than educational classes of childbirth in decreasing of application of analgesic medication. Dazzling participants do not have the favorable effect within the study of hypnotherapy because their thoughts about the therapy nature are totally to its mechanism of psychological change. Psycho-social interventions which purpose for improving mental health for a diversity of problems and symptoms can be elevated by expressing and relabeling them as hypnosis. Consequently, having connection with participants which experiencing hypnosis would be a favorable characteristic in studies of the hypnosis impression for management of delivery and labor pain.

\section{Conclusion}

One of the most general experiences of women worldwide is childbirth and the pain correlated with delivery and childbirth could be very worrying. In spite of the fact that, various pharmacologic procedures could be impressive in reduction of delivery and labor discomfort, the application of them would not be without risk. ${ }^{13}$ In accordance with the literature there is not considerable scientifically research around the hypnosis productiveness for management of delivery pain. Due to this fact, the studies related to the application of hypnosis for decreasing delivery pain have fall behind other regions of study. Accordingly, the future studies should be directed to the multiplication of methodological researches that assessing this promising which are not proved accurately for delivery and childbirth pain.

\section{List of acronyms}

PET - Positron emission tomography

PTSD - post-traumatic stress disorder

SVD - Spontaneous vaginal delivery

\section{Authors contributions}

Both authors played a substantial role in conception, data acquisition and analysis, as well as drafting of the manuscript.

\section{Acknowledgments None.}

Funding No funding was obtained for this project.

\section{Conflict of Interest}

The authors declare they have no conflicts of interest.

\section{Ethical Publication Statement}

We confirm that we have read the Journal's position on issues involved in ethical publication and affirm that this report is consistent with those guidelines.

\section{Corresponding Author}

Sima Azizmohammadi, Department of Gynecology, AJA University of Medical Sciences, Tehran, Iran.

Phone: 00989121057715

Email: Simaazizmohammadi@yahoo.com

\section{E-mail of co-author}

Susan Azizmohammadi: dr.azizmohamadi@gmail.com

\section{References}

1. Yaqub F. Pain in the USA: states of suffering. Lancet 2015;386 (9996): 839.

2. Madden K., Middleton P, Cyna AM, et al. Hypnosis for pain management during labour and childbirth. Cochrane Database Syst Rev 2016;5:CD009356.

3. Landolt AS, Milling LS. The efficacy of hypnosis as an intervention for labor and delivery pain: a 
comprehensive methodological review. Clin Psychol Rev 2011;31: 1022-31.

4. Donald CB, Corydon H. Evidence-Based Clinical Hypnosis for Obstetrics, Labor and Delivery, and Preterm Labor. Expert Review Neurotherapeutics 2006;10:263-73.

5. Madden K, Middleton P, Cyna AM, Matthewson $\mathrm{M}$, et al. Hypnosis for pain management during labour and childbirth. Cochrane Database Syst Rev 2012;11:CD009356.

6. Smith CA, Collins CT, Cyna AM, Crowther CA. Complementary and alternativetherapies for painmanagement in labour(Cochrane Review). 2004. In: The Cochrane Library. Chichester, UK: John Wiley \& Sons, Ltd, 1.

7. Howell CJ. Epidural versus non-epidural analgesia for pain relief in labour (Cochrane Review). 2004. In: The Cochrane Library. Chichester, UK: John Wiley \& Sons Ltd; 1.

8. Vgontzas A, Robbins M. A Hospital Based Retrospective Study of Acute Postpartum Headache. Headache. 2018;58:845-51.

9. Cyna AM. Hypno-analgesia for a labouring parturient with contraindications to central neuraxial block. Anaesthesia 2003;58:101-2.

10. Unyime I, Ashraf S. H. Enhanced recovery after cesarean delivery. 2018. Version 1. F1000Res; 7: F1000 Faculty Rev-513.

11. Farnad I, Poupak R, Hamid-Reza F, et al. Comparison of the Post-Caesarean Analgesic Effect of Adding Dexmedetomidine to Paracetamol and Ketorolac: A Randomized Clinical Trial. Anesth Pain Med 2018;8:e85311.

12. Cyna AM, Andrew MI, McAuliffe GL. Antenatal self-hypnosis for labor and childbirth: A pilot study. Anesthesia Intensive Care 2006;34:464-9.

13. VandeVusse L, Irland J, Healthcare WF, et al. Hypnosis for childbirth: A retrospective comparative analysis of outcomes in one obstetrician's practice. American Journal of Clinical Hypnosis 2007:50:109-19.

14. Jenkins MW, Pritchard MH. Hypnosis: Practical applications and theoretical considerations in normal labour. British Journal of Obstetrics and Gynaecology 1993;100:221-6.

15. Martin A, Schauble P, Rai S, Curry, R. The effects of hypnosis on the labor processes and birth outcomes of pregnant adolescents. Journal of Family Practice 2001;50:441-3.

16. Letts PJ, Baker PRA, Ruderman J, Kennedy K. The use of hypnosis in labor and delivery: A preliminary study. Journal of Women's Health 1993;2:335-41.

17. Mehl-Madrona L. Hypnosis to facilitate uncomplicated birth. American Journal of Clinical Hypnosis 2004;46:299-312.

18. Venn J. Hypnosis and Lamaze method - An exploratory study: A brief communication.
International Journal of Clinical and Experimental Hypnosis 1987;35:79-82.

19. Jensen MP, Patterson DR. Hypnotic approaches for chronic pain management: clinical implications of recent research findings. Am Psychol 2014;69:16777.

20. Jensen MP, Adachi T, Tomé-Pires C, et al., Mechanisms of hypnosis: toward the development of a biopsychosocial model. Int J Clin Exp Hypn 2015;63:34-75.

21. Australian and New Zealand College of Anaesthetists and Faculty of Pain Medicine Working Party: Acute Pain Management: Scientific Evidence. 2005. Melbourne: NHMRC endorsed guidelines.

22. Smith CA, Collins CT, Cyna AM, Crowther CA. Complementary and alternative therapies for pain management in labour. Cochrane Database Syst Rev 2003;CD003521.

23. Bailham D, Joseph S. Post-traumatic stress following childbirth: a review of the emerging literature and directions for research and practice. Psych Health Med 2003;8:159-68.

24. Montgomery GH, Weltz CR, Seltz M, Bovbjerg DH. Brief presurgery hypnosis reduces distress and pain in excisional breast biopsy patients. Int $\mathrm{J}$ Clin Exp Hypn 2002;50:17-32.

25. Cyna AM, McAuliffe G, Andrew MI. Hypnosis for pain relief in childbirth: a systematic review. British Journal of Anaesthesia 2004;93:505-11.

26. Faymonville M, Boly M, Laureys S. Functional neuroanatomy of the hypnotic state. J Physiol Paris 2006;99:463-9. Epub 2006 Jun 5.

27. Koyama T, McHaffie JG, Laurienti PJ, et al. The subjective experience of pain: where expectations become reality. Proc Natl Acad Sci 2005;102:12950-5.

28. Gamsa A. Hypnotic Analgesia. In Handbook of Pain Management Edited by: Melzack R, Wall PD. Sydney: Curchill Livingstone. 2003;521-31.

29. Mathieu L, Moriah S, Michel L, et al. Hypnosis in palliative care: from clinical insights to the science of self-regulation. Ann Palliant Med 2018;7:12535.

30. Cyna AM, Andrew MI, McAuliffe GL. Antenatal hypnosis for labour analgesia. Int J Obstet Anesth 2005;14:365-6.

31. Huntley AL, Coon JT, E. Complementary and alternative medicine for labor pain A systematic review. American Journal of Obstetrics and Gynecology 2004;191:36-44.

32. Whitburn L, Jones L, Davey M, McDonald S. The nature of labour pain: An updated review of the literature. Women Birth 2019;32:28-38.

33. Wendy C, Mieke V, Piet FB. Childbirth expectations and experiences in Belgian and Dutch models of maternity care. Journal of Reproductive and Infant Psychology 2008;26:309-22. 


\section{Hypnotherapy in delivery pain}

Eur J Transl Myol 29 (3): 210-217, 2019

34. Grantly DR. Childbirth Without Fear: The Principles and Practice of Natural Childbirth. 2013. Kindle Edition, London.

35. Akinyemi K, Adeyemo A, Ogundeji K. Pain Relief during Labor: Attitudes of Postpartum Mothers in Selected Hospitals in Ibadan, Nigeria. Journal of Midwifery and Reproductive Health 2018;6: 141421.

36. Lawrence A, Lewis L, Hofmeyr GJ, et al. Maternal positions and mobility during first stage labour. Cochrane Database of Systematic Reviews, 2009;2.

37. Hodnett ED, Gates S, Hofmeyr GJ, et al. Continuous support for women during childbirth. Cochrane Database of Systematic Reviews 2011;2.

38. Chooi CSL, Nerlekar R, Raju R, Cyna AM. The effects of positive or negative words when assessing postoperative pain. Anaesthesia and Intensive Care 2011;39:101-6.

39. Thompson T, Mendoza ME, Docking R. Pain management and assessment. In: Docking, R.E., Stock, J. (Eds.), International Handbook of Positive Aging. Routledge, London, UK. 2017, pp. 115-131.

40. Eason AD, Parris BA. Clinical applications of selfhypnosis: A systematic review and meta-analysis of randomized controlled trials. Psychology of Consciousness: Theory, Research, and Practice. 2018. Advance online publication.
41. Saiideh N, Fatemeh M, Fariba S. Effectiveness of Trainings Based on the Theory of Reasoned Action in the Choice of Natural Delivery by Pregnant Women. International Journal of Women's Health and Reproduction Sciences 2018;6:181-6.

42. Cyna A, Crowther C, Robinson J, et al. Hypnosis antenatal training for childbirth: a randomised controlled trial. BJOG 2013;120:1248-59; discussion 1256-7.

43. Werner A. Antenatal Hypnosis Training - the Effect on Pain Expereince, Duration of Birth and other Birth Outcomes (PhD thesis). 2013. Aarhus University.

44. Downe S. Self-hypnosis for intrapartum pain management (ship) trial. ISRCTN Registry (http://www.isrctn.com/), 2015.

45. Stoelb B, Molton I, Jensen M, Patterson D. The efficacy of hypnotic analgesia in adults: A review of the literature. Contemporary Hypnosis, 2009;26:24-39.

46. Reinhard, J. Heinrich, T. M., Reitter, A., et al. Clinical hypnosis before external cephalic version. American Journal of Clinical Hypnosis 2012;55, 184-192.

Submission: June, 27, 2019

Acceptance: July 05, 2019 